\title{
Editorial: Challenges and Opportunities for Services Marketers in a Culturally Diverse Global Marketplace
}

Purpose: The aim of this special issue is to extend the growing research on the challenges and opportunities facing services marketers in an increasingly culturally diverse global marketplace.

Methodology: The nine papers included in this special issue use a variety of research methods (e.g., case study, experiments and surveys), participants (e.g., customers, employees and online panel members) and service settings (e.g., fast food, post office, weight loss, bank, home loan, personal fitness and offshore outsourcing).

Findings: All the nine papers highlight the importance of studying the unique perspectives of the customers and employees involved in intercultural interactions in diverse service settings in marketplaces and societies that are either already or have recently become multicultural.

Research limitations/implications: The findings from the nine papers have useful implications for future research on services marketing in multicultural markets although these may not always be generalizable beyond the unique context of the studies reported in each of these papers.

Practical implications: All the nine papers also present some useful directions for services marketing managers in the multicultural markets, to help them understand and manage the expectations of their culturally diverse customers as well as employees.

Originality/value: This special issue is unique because it is one of the first attempts to understand the unique challenges and opportunities for services marketers in the growing multicultural global marketplace, from a theoretical as well as empirical point-of-view. 


\section{Introduction}

In the last few decades, globalization has led to an increase in international travel, tourism and immigration, which in turn are creating a culturally diverse and complex global marketplace by bringing together customers and employees from different cultural and ethnic backgrounds (Sharma, Tam and Kim, 2009, 2012; Sharma et al., 2017). For example, there were more than 250 million international immigrants in the world by the end of 2017, which accounts for 3.4 percent of the global population, representing an increase of 105 million since 1990 (United Nations, 2017). In addition, number of international tourists crossed 1.3 billion in 2017 and generated revenues of about US\$1.5 trillion, which represents about $10 \%$ of global GDP, $7 \%$ of global exports and 30\% of total services exports (UNWTO, 2018). After adding the number of people traveling overseas for education, employment and business for relatively shorter durations, it is quite likely that more than 2 billion people (about one-fourth of world population) are currently in a country different from the one they were born in. This huge figure highlights the growing cultural and ethnic diversity around the world today (Euromonitor International, 2015).

Such a dramatic rise in the cultural and ethnic diversity offers new challenges and opportunities for services marketers because the culturally diverse customers and employees have significantly different expectations, perceptions and evaluations about service quality and its various dimensions (Etgar and Fuchs, 2011; Morales and Ladhari, 2011; Schoefer, 2010).While the increase in the number of such intercultural interactions offer additional business opportunities to both local and global services marketers, it also makes it difficult to design appropriate service offers to match the unique needs of culturally diverse customers and to deliver these through their service employees who may be used to a mono-cultural service 
environment (Sharma et al., 2014; Sharma and Zhan, 2015). Interestingly, such intercultural interactions are already a regular phenomenon in most multi-cultural societies such as United States, UK and Singapore among the developed countries and India, Brazil and South Africa among the emerging markets (Demangeot, Broderick and Craig, 2015).

Early research on multicultural markets mostly used a descriptive approach to explore the role of variables, mainly from the customers' point of view, such as culture shock (Stauss and Mang, 1999), perceived discrimination (Barker and Härtel, 2004), cross-cultural interaction comfort (Paswan and Ganesh, 2005), consumer ethnocentrism (Javalgi and Martin, 2007; Sharma, Sivakumaran and Marshall, 2005; Ueltschy et al., 2007), and ethnic/cultural dissimilarity (Etgar and Fuchs, 2011). Others explored customer reactions to service failure and recovery (de Matos et al., 2011) and to employee’s acculturation behaviours (Poulis, Poulis and Yamin, 2013), ethnic accents (Tombs and Rao Hill, 2014) and attentiveness (Lee, 2015). Customers were also shown to indulge in some amount of cultural or national stereotyping when choosing a service provider, showing a clear preference for those from similar cultural, ethnic or national background as theirs (Hopkins, Hopkins and Hoffman, 2005; Javalgi and Martin, 2007; Ueltschy et al., 2007), while customers from minority cultures reported being discriminated against by the service employees from the majority culture (Barker and Härtel, 2004).

Subsequent studies examined the role of employee stress and coping (Wang and Mattila, 2010), cross-cultural consumer to consumer interactions (Johnson and Grier, 2013), emotional labour (Chuapetcharasopon, 2014), preference for ethnic service staff (Baumann and Setogawa, 2014), attributions (Tam, Sharma and Kim, 2014) and intercultural communication competence (Ihtiyar and Ahmad, 2015) in intercultural service encounters. More recent studies explore the 
roles of moderators such as service role and outcome (Sharma, Tam and Kim, 2015), consumer ethnocentrism and intercultural competence (Sharma and Zhan, 2015) and personal cultural orientations (Sharma, Zhan and Su, 2016), while others examine the role of acculturation behaviours by frontline service employees in shaping customer satisfaction and commitment (Gaur et al., 2017) and the mediating role of intercultural service quality in the influence of service climate on employee performance in multicultural service settings (Fung et al., 2017).

Despite growing research on the increasingly culturally diverse global marketplace, there are still many important research gaps and unanswered questions, some of which are addressed in this special issue. Specifically, this special issue aims to extend the growing research on the challenges and opportunities facing services marketers in the multicultural global economy, with nine articles that address the unique challenges and opportunities offered by the differences in the expectations, perceptions and evaluations of customers and service employees in their intercultural interactions in today’s culturally diverse global marketplace. The theoretical and empirical insights offered by these articles would help services marketing scholars look beyond the typical mono-cultural or cross-cultural views of customer-employee interactions that have been prevalent in services marketing literature. This special issue will also help services marketers recognize the importance of understanding and accepting cultural differences between and among their customers and employees in multi-cultural societies and develop suitable strategies to manage these differences in their service design and delivery processes.

\section{Literature Review}

Last few decades have seen a rapid rise in the number of interactions among customers and employees from diverse cultural backgrounds as increasing numbers of international travellers 
and immigrants go about their lives in their host cultures, by learning about and adjusting to the challenges posed by their unfamiliar socio-cultural environments (Kim, 2015; van Oudenhoven and Benet-Martínez, 2015; Yu and Lee, 2014). Interestingly, the customers and employees in the host cultures also experience a similar process because they too have to understand and adjust to these foreigners visiting or even making their homes in their countries (Liu and Morris, 2014). , In this process, both customers and employees from diverse cultures need to overcome their perceived cultural distance with each other and learn to adjust their own behaviours, in view of the significant differences between them, in terms of language, ethnicity, physical appearance, personal and social values as well as behavioural norms.

In this context, past research shows that intercultural interactions may help people to experience and learn about other cultures, and over time possibly even successfully acculturate (i.e., learn about and adjust with other cultures than their own). However, being forced to face intercultural interactions may also prove to be rather challenging for many people, particularly if they lack knowledge about other cultures or if they are not willing or able to learn about and accept cultural differences, which may involve changing their behaviours through acculturation (Berry, 1974, 2005) if they are immigrants and through cross-cultural adjustment (Ward and Kennedy, 2001; Ward and Rana-Deuba, 2000) if they are temporary visitors, such as students, expatriate workers, foreign tourists or business visitors.

Early research on intercultural interactions focused on the challenges faced by in the process of cross-cultural adjustment mostly by international travellers (Brein and David, 1971) in the beginning and subsequently by expatriate managers (Janssens, 1995). Researchers also examined the role played by intercultural communication (Condon and Yousef, 1975; Samovar, 
Porter and Jain, 1981) in the process of cross-cultural adaptation, and identified several barriers that either inhibit the process of cross-cultural adjustment and prevent effective intercultural communications, including psychological privilege and ethnocentrism (Thomas, 1996), or promote intercultural interactions, such as intercultural competence (Lustig and Koester, 2006) and willingness to communicate ( $\mathrm{Lu}$ and $\mathrm{Hsu}, 2008$ ). More recent studies explore the outcomes of intercultural interactions, such as employee performance (Sanchez-Burks, Bartel and Blount, 2009), cooperation and competition (Matsumoto and Hwang, 2011) and the process by which people from diverse cultures form their unique cultural identities (Liu and Morris, 2014).

Past research links intercultural interactions with several problems that could potentially debilitate social cohesion and harmony, such as ethno-cultural identity conflict (Leong and Ward, 2000; Ward, 2008), misattributions, communication gaps, stereotyping, ethnocentrism, prejudice and discrimination (Stening, 1979), and intolerance, confrontation and even violence towards ethnic minorities (Johnson, Meyers and Williams, 2013). It is interesting to see these concerns raise their heads in the $21^{\text {st }}$ century with the rise of right-wing political parties across the world, from Australia to United States, Japan to India and United Kingdom to France, which could potentially threaten the move towards globalisation and open borders, by focusing on the possible 'evils' of immigration and the 'ill-effects' of rising multiculturalism in their societies. However, despite the above negative associations, intercultural interactions are now being increasingly recognized as an unavoidable feature of an already globalised world economy and the resulting multicultural global marketplace (Demangeot et al., 2015; Tam et al., 2014), which in turn is making global services marketers and academic scholars alike, realise the urgent need to understand the challenges and opportunities offered by the wide range of cultural, ethnic, 
national and socio-economic differences between customers and service employees in multicultural marketplaces in both developed and emerging markets around the world (Chuapetcharasopon, 2014; Sharma et al., 2015; Sharma et al., 2017; Sharma and Zhan, 2015).

\section{Research Gaps}

Notwithstanding the significant contribution of past research on the challenges and opportunities for services marketers in the culturally diverse markets, there are still many unanswered questions and unresolved research gaps. For example, most of the research in this area mainly focuses on the customers' perspective and that too in the context of intercultural service encounters in the business-to-consumers (B2C) services (Gaur et al., 2017; Sharma et al., 2009, 2012, 2015; Sharma and Zhan, 2015; Sharma et al., 2016; Tam et al., 2014; Tam, Sharma and Kim, 2016), with hardly any research on the Business-to-business (B2B) contexts and intercultural interactions among employees in a multicultural workplace (e.g., Fung et al., 2017), both of which constitute substantially large components of the global marketplace that has become quite multicultural in recent years and continues to grow even more. In addition, there is still no comprehensive conceptual framework that could explain the ways in which cultural differences shape customer and employee expectations, perceptions and evaluations in monocultural, multi-cultural and intercultural service encounters. Such a framework would be able to guide future research on this topic of growing importance.

There is hardly any research that examines the differences in the impact of individuallevel personal cultural values and national cultural dimensions on customers and employees involved in intercultural service encounters. As a result, services marketers do not have enough knowledge that could help them develop appropriate processes and delivery mechanisms for 
their services in order to satisfy the widely different expectations of their culturally diverse customers and employees. Similarly, the interactions among cultural, socio-economic and demographic variables in their influence on the expectations, perceptions and evaluations of the culturally diverse groups of customers and employees also remain unexplored.

In terms of theoretical perspectives, recent research on intercultural service encounters uses theories such as role theory, social-identity theory, similarity-attraction paradigm and attribution theory; however, there is a scope to further strengthen the conceptual foundations by exploring the role of other psychographic and socio-psychological processes such as stereotypes and acculturation (cross-cultural adjustment and adaptation) in intercultural service encounters. Moreover, we need to differentiate and investigate the role of constructs such as intercultural competence, intercultural sensitivity and cultural intelligence in intercultural service encounters, which may provide insights into the cross-sectional versus developmental perspective of crosscultural adjustment and adaptation by examining the influence of different stages of crosscultural adjustment on culturally diverse customers and employees.

Next, in terms of managerial implications, there is a great deal of scope to make a contribution to the services marketing discipline. For example, further research on the marketing strategies used by both local and global services marketers in their markets (e.g., standardization vs. customization, localization vs. globalization), would help us understand and address the cultural differences among their customers and employees in the growing multicultural markets. Similarly, research on the reasons and outcomes of intercultural friction and conflict between service employees and customers, and the resolution strategies used by the service firms to avoid service failure and manager service recovery, would provide insights on how to foster trust and 
relationship in in multicultural service settings. In this context, the role of internal marketing in creating a service culture among culturally diverse employees inside the service firms could be examined as a means to deal with culturally diverse customers in multicultural markets.

In a similar vein, we need more research on the unique nature and contribution of the marketing mix elements in culturally diverse marketplaces, such as the design and delivery of the core product or service including service features and delivery process, employee selection and training, servicescape design and customer experience management to understand and manage the expectations and perceptions of culturally diverse customers and employees. To this end, it would also be important to study the role of market research, service innovation and co-creation in identifying and developing new services to cater to culturally diverse customers. In addition, researchers could identify and study the specific human resources management (HRM) strategies used in these markets to recruit, train and retain culturally competent frontline service employees. Finally, we need more research on the influence of emerging themes such as corporate social responsibility, environment protection and sustainability in the multicultural global marketplace.

This special issue consists of nine papers that address some of the above research gaps and unresolved issues, such as the influence of linguistic choices, language homophily, perceived cultural distance and (mis)match on customer perceptions and behaviours, impact of intercultural competence on frontline service employees’ recognition of their customers’ faces, role of customer participation on their attributions, impact of technology readiness on young consumers' socialisation, and the role of intercultural workplace behaviours and business-to-business interactions in multicultural service settings, as described in the next section. In addition, Table 1 also provides a snapshot of the past and current research on a variety of topics as well as 
directions for further conceptual and empirical contributions that could be made in this research area of growing importance for international services marketers.

$<$ Insert table 1 about here $>$

\section{Special issue}

The first paper in this special issue, titled "Customer response to service encounter linguistics" (Zolfagharian, Hasan and Iyer, 2018), investigates the impact of service employees' choice and use of language in multicultural service encounters on their customers' evaluations of interaction quality, service quality, and satisfaction as well as customer loyalty, identification with the brand, and positive word-of-mouth (WOM) intentions. The authors use a 3 (contexts: fast food-English; post office-English; post office-Spanish) $\times 4$ (scenarios: customer language preference adhered to; adapted to; mixed; ignored) between-subjects scenario-based experiment with Mexican American consumers in the United States, to show that customers perceive higher or at least equal level of interaction quality when employee use their preferred language from the beginning than when the employee switches to their preferred language after missing it initially. Both these scenarios also exhibit higher interaction quality than those in which the employee ignores customer language preference or use elements from two languages throughout the interaction. The negative impact of ignoring customer preferred language or mixing it with another language are amplified for customers with low ethnic identification and among those with lower level of bilingualism. These findings add to the literature that examines the dynamics of intercultural service encounters and draws attention to employee choice and use of language and its impact on a host of service outcomes, with interaction quality serving as a key mediator. This study 
highlights the need for service firms to consider customer language preferences and train and empower employees to meet customer expectations.

The second paper, titled "Perceived cultural distance in intercultural service encounters: does customer participation matter?” (Ang, Liou and Wei, 2018), investigates the negative effect of perceived cultural distance on service quality and customer satisfaction through customers' social judgements of the service providers' warmth and competence in intercultural service encounters, and the mitigation of this negative effect through customer participation. The authors use a 2x2 between-subjects experimental design with an online consumer panel and deploy a series of intercultural service encounter scenarios in a weight loss service context, to manipulate customer participation (high vs. low) and pictures of service providers to induce perceived cultural distance (high vs. low). As hypothesized, they find that in the context of intercultural service encounters, perceived cultural distance negatively impacts customers' social judgements of the service providers' warmth and competence, which in turn influence service quality and customer satisfaction. However, the negative impact of PCD is diminished when the level of customer participation is high. These findings may help services marketers in multicultural marketplaces improve their customers' experience by designing the service delivery process in ways that allows for more customer engagement and participation. This study is among the first attempts to highlight the importance of consumers' social judgements about culturally dissimilar service providers, which can be influenced through greater customer participation.

The third paper, titled “Attributions of service quality: immigrant customers’ perspective” (Sichtmann and Micevski, 2018), investigates the impact of cultural (mis)match on immigrant customers' satisfaction and the mediating role of cultural and employee performance 
attributions in this relationship. In addition, the authors test the moderating effect of service delivery outcome (success vs. failure) on the above process. The authors use a 2 (origin of service employee: Austria or Turkey) $\times 2$ (service delivery outcome: success or failure) scenariobased experiment in a financial service (bank) setting with 120 Turkish immigrant customers in Austria, to show that cultural (mis)match does not have a significant direct effect on customer satisfaction. However, for a positive service delivery outcome, immigrant customers attribute the results to the cultural background of the employee if it is the same as their home culture, but they attribute success to employees’ performance if they belong to the host culture. In contrast, negative service delivery outcomes do not give rise to either cultural or performance attributions. These results challenge the predictions of social identity theory and the similarity-attraction paradigm as reported in prior research and highlight that customer attributions may play a more prominent role in influencing the satisfaction levels of immigrant customers.

The fourth paper, titled "Intercultural competence and customer facial recognition” (Henderson et al., 2018), explores the effect of racial identification on customer-employee interactions. The authors use two experiments in the United States and South Africa to show how intercultural competence impacts recognition of Black and White consumer faces. They find that the respondents with higher levels of intercultural competence with Blacks are better at distinguishing between Black regular customers and Black new shoppers in an experiment. However, there is no impact of intercultural competence on the ability of respondents to differentiate between White consumers. This study highlights the impact of frontline service employees' ability to recognise their regular customers' faces can affect the quality of their interactions and customer satisfaction in today’s increasingly multicultural marketplaces. 
The fifth paper, titled "Does language homophily affect migrant consumers' service usage intentions?” (Pezzuti, Pierce and Leonhardt, 2018), investigates the impact of language homophily between service providers and migrant consumers on the migrant consumers’ intentions to engage with financial and medical service providers. The authors use three empirical studies with migrant consumers living in Chile, England, and the United States, to provide the participants with information on service providers and manipulate language homophily using a between-subjects design. In the high (low) language homophily condition, service providers were described as having (not having) the ability to speak the native language of the migrant consumer. Language homophily was found to increase migrant consumers' expectation of control over a service encounter and, in turn, increase their intention to use a provider's services. Collectivism was identified as a boundary condition, wherein language homophily did not affect service usage intentions among high collectivist consumers but it did positively affect service usage intentions among low collectivist consumers. This study extends prior research on service provider language by showing a positive effect of language homophily on service usage intentions and by identifying mediating (i.e., expected control over the outcome of the service encounter) and moderating (i.e., collectivism) mechanisms for this effect.

The sixth paper, titled "Technology readiness of teenagers: A consumer socialization perspective” (Mishra, Maheswarappa and Colby, 2018), explores the role of culture-specific socialization factors as antecedents to Technology Readiness Index (TRI) scale to understand the adoption of cutting edge technologies among teenagers in a multicultural emerging market, India. The authors use survey data from 381 Indian teenagers to show that parent-child communication, peers, media, and self-construal have varying levels of influence on technology readiness of teenagers. The effects of parent-child interactions are mediated by self-construal that reaffirms 
the importance of identity during adolescence. The findings from this study highlight that culture-specific characteristics are critical antecedents to teenagers' TRI; however, the TRI 2.0 scale may need to be refined to be used in those culturally diverse marketplace in which consumers are less familiar with the technical terms used in developed countries and display low levels of technology awareness. In addition, marketers may need to tailor their communication strategies to have a strong presence on digital media to engage with teenagers. Firms could also utilize media to provide information and develop content that should resonate with teens and potentially enhances their online impression to increase the adoption of technology.

The seventh paper, titled "Australian Muslim women and fitness choices - myths debunked” (Summers et al., 2018), explores the impact of religiosity on the attitudes of Muslim women living in Australia toward exercise and gym attendance. This is an interesting study in view of the recent anti-Islamic sentiments expressed in several Western countries in response to the rise of militancy and extremism in many Muslim countries. The findings from this study debunk the myth about religious oppression of Islamic women that deprives them of their basic rights to their own bodies through exercise choices. The authors highlight that, in fact, this segment represents an untapped opportunity for the fitness industry. The results of this study add to the understanding of motivations for fitness participation of multi-cultural minority groups such as Muslim Women in Australia. In addition, the Muslim market is shown to be diverse and unbounded, concluding that whilst religion can be a useful starting point for segmentation, care is needed not to overemphasise faith at the expense of other aspects of identity.

The eighth paper, titled "Service models and culture: impact on work behaviours" (Mathies and Wong, 2018), explores the influence of the cultural values of frontline employees 
(FLEs) on their work behaviours. Specifically, the authors draw on the organisational behaviour literature to investigate the impact of culture and service models on emotional labour and organisational citizenship behaviour (OCB), and the resultant psychological well-being of FLEs. Findings from their study in two countries (US and India) may help both researchers and practitioners who seek to reap competitive advantages from good customer service. The study results contribute to the cross-cultural customer service literature by demonstrating the links between service models and work behaviours contingent on FLE’s cultural values. Practitioners in service firms may gain additional insights into managing their culturally diverse FLEs to encourage delivery of high quality service while safeguarding their psychological well-being. This is crucial because FLEs are the face of service brands and their behaviours have a major influence on customers’ perceptions of service quality and satisfaction.

Finally, the ninth paper in this special issue, titled "Power, resource-dependencies and capabilities in intercultural B2B relationships” (Malik, Ngo and Kingshott, 2018), explores the impact of organisational resources and capabilities on relationship quality and firm performance in the context of high-technology offshore outsourcing service vendors. The authors use a qualitative case study design to collect and analyse data from four offshore business process and information technology outsourcing firms based in India. Findings highlight that resourcedependence, cultural orientation and the vendor's resources and capabilities strengthens relationship quality and impacts firm performance. This study identifies key organisational mechanisms that improve relationship quality and firm performance, and helps understand the adverse effects of ethnocentricity and power faced by vendors and subsidiaries within diverse intercultural contexts. This study is one of the first to examine intercultural interactions in a business-to-business context, which are quite common in multicultural workplaces and yet have 
somehow been ignored in the past research on intercultural service encounters. We hope that it would trigger interest among academic researchers to further explore this phenomenon.

\section{Discussion and future research directions}

This special issue is one of the few attempts to extend the growing research on the challenges and opportunities facing services marketers in the increasingly culturally diverse global marketplaces. While most of the past research in this area focused on the socio-psychological process underlying intercultural service encounters, the guest editors of this special issue specifically called for fresh theoretical perspectives and empirical approaches to provide both broader and deeper insights into the factors that drive the expectations, perceptions and evaluations of consumers in multicultural societies in developed as well as emerging markets. The papers included in this special issue address a variety of topics, including the impact of linguistic choices and language homophily as well as perceived cultural distance and (mis)match between culturally diverse customers and service employees on their service experience, the effects of intercultural competence on frontline employees' recognition of their regular culturally diverse customers and technology readiness on teenage customers in a multicultural market. Besides the above topics, the last two papers in this special issue also explore intercultural workplace behaviours and business-to-business interactions, in multicultural service settings.

All the papers included in this special issue make a useful contribution to our knowledge and understanding of the services customers and service employees in multicultural markets; however there are still many unaddressed issues and unanswered questions that future research may address. First, most current research on this topic is still restricted to only a few countries, such as Australia (Summers et al., 2018), India (Malik et al., 2018; Mathies and Wong, 2018; 
Mishra et al., 2018) and United States (Ang et al., 2018; Mathies and Wong, 2018; Zolfagharian et al., 2018), with some exceptions such as Austria (Sichtmann and Micevski, 2018) and Chile (Pezzuti et al., 2018). Hence, we need more studies in other countries that have traditionally been multi-cultural, such as Brazil, UK, Singapore and Malaysia as well as those that have become multi-cultural more recently as a result of the rise in immigration, such as Germany, France and Italy. Second, most studies on this topic still continue to focus on the customers' perspective in business-to-consumer services although some have begun to investigate the service employees’ point-of-view (e.g., Henderson et al., 2018; Mathies and Wong, 2018) and business-to-business services (Malik et al., 2018). We clearly need more research in a wider variety of multicultural and cross-cultural service settings, representing a broader range of perspectives, including service customers, frontline employees, salespeople, after-sales service providers.

Finally, the papers in this special issue examine the impact of several important variables, such as language (e.g., linguistic choices and language homophily), cultural distance (e.g., perceived cultural distance and cultural (mis)match), intercultural competence, customer attributions and customer participation, customer technology readiness, intercultural workplace behaviours and business-to-business interactions in multicultural environments. However, these are clearly by no means an exhaustive set of variables that could influence the expectations, perceptions and evaluations of customers and employees in multicultural marketplaces. Hence, future research should aim to identify and explore the roles of other relevant variables, such as cultural stereotypes, perceived discrimination, and consumer ethnocentrism, to pave the way for a more comprehensive conceptual framework. 


\section{References}

Ang, T., Liou, R.-S. and Wei, S. (2018), "Perceived cultural distance in intercultural service encounters: does customer participation matter?", Journal of Services Marketing, Vol. 32 No. 4.

Barker, S. and Härtel, C.E.J. (2004), "Intercultural Service Encounters: An Exploratory Study of Customer Experiences", Cross Cultural Management: An International Journal, Vol. 11 No. 1, pp. 3-14.

Baumann, C. and Setogawa, S. (2014), "Asian ethnicity in the West: preference for Chinese, Indian and Korean service staff", Asian Ethnicity, Vol. No., pp. 1-19.

Berry, J.W. (1974), "Psychological aspects of cultural pluralism", Topics in Culture Learning, Vol. 2 No., pp. 17-22.

Berry, J.W. (2005), "Acculturation: Living successfully in two cultures", International Journal of Intercultural Relations, Vol. 29 No. 6, pp. 697-712.

Brein, M. and David, K.H. (1971), "Intercultural communication and the adjustment of the Sojourner", Psychological Bulletin, Vol. 76 No. 3, pp. 215-230.

Chuapetcharasopon, P. (2014), Emotional Labour in the Global Context: The Roles of Intercultural and Intracultural Service Encounters, Intergroup Anxiety, and Cultural Intelligence on Surface Acting. University of Waterloo.

Condon, J.C. and Yousef, F.S. (1975), An introduction to intercultural communication, ed., MacMillan Publishing Company, Indianapolis, IN. 
de Matos, C.A., Fernandes, D.V.d.H., Leis, R.P. and Trez, G. (2011), "A Cross-Cultural Investigation of Customer Reactions to Service Failure and Recovery", Journal of International Consumer Marketing, Vol. 23 No. 3-4, pp. 211-228.

Demangeot, C., Broderick, A.J. and Craig, C.S. (2015), "Multicultural marketplaces: New territory for international marketing and consumer research", International Marketing Review, Vol. 32 No. 2, pp. 118-140.

Etgar, M. and Fuchs, G. (2011), "Does Ethnic/Cultural Dissimilarity Affect Perceptions of Service Quality?", Services Marketing Quarterly, Vol. 32 No. 2, pp. 113-128.

Euromonitor International (2015). "Cultural Diversity and its Impact on Global Consumer Markets". pp. 70.

Fung, C., Sharma, P., Zhan, W. and Su, Y. (2017), "Exploring service climate and employee performance in multicultural service settings", Journal of Services Marketing, Vol. 31 No. 7, pp. 784-798.

Gaur, S.S., Sharma, P., Herjanto, H. and Kingshott, R. (2017), "Impact of frontline service employees’ acculturation behaviors on customer satisfaction and commitment in intercultural service encounters", Journal of Service Theory and Practice, Vol. 27 No. 6, pp. 1105-1121.

Henderson, G., White, T., Rank-Christman, T., Grantham, K., Ostrom, A. and Lynch, J. (2018), "Intercultural Competence and Customer Facial Recognition", Journal of Services Marketing, Vol. 32 No. 4. 
Hopkins, S.A., Hopkins, W.E. and Hoffman, K.D. (2005), "Domestic inter-cultural service encounters: an integrated model", Managing Service Quality, Vol. 15 No. 4, pp. 329-343.

Ihtiyar, A. and Ahmad, F.S. (2015), "The Impact of Intercultural Communication Competence on Service Quality and Customer Satisfaction", Services Marketing Quarterly, Vol. 36 No. 2, pp. 136-152.

Janssens, M. (1995), "Intercultural interaction: a burden on international managers?", Journal of Organizational Behavior, Vol. 16 No. 2, pp. 155-167.

Javalgi, R.G. and Martin, C.L. (2007), "Internationalization of services: identifying the buildingblocks for future research", Journal of Services Marketing, Vol. 21 No. 6, pp. 391-397.

Johnson, G.D. and Grier, S.A. (2013), "Understanding the influence of cross-cultural Consumerto-Consumer Interaction on consumer service satisfaction", Journal of Business Research, Vol. 66 No. 3, pp. 306-313.

Johnson, G.D., Meyers, Y.J. and Williams, J.D. (2013), "Immigrants versus nationals: When an intercultural service encounter failure turns to verbal confrontation", Journal of Public Policy \& Marketing, Vol. 32 No. Special issue, pp. 38-47.

Kim, Y.Y. (2015), "Finding a "home" beyond culture: The emergence of intercultural personhood in the globalizing world", International journal of intercultural relations, Vol. 46 No. 1, pp. 3-12. 
Lee, H.E. (2015), "Does a server's attentiveness matter? Understanding intercultural service encounters in restaurants", International Journal of Hospitality Management, Vol. 50 No. 1, pp. 134-144.

Leong, C.-H. and Ward, C. (2000), "Identity conflict in sojourners", International Journal of Intercultural Relations, Vol. 24 No. 6, pp. 763-776.

Liu, Z. and Morris, M.W. (2014), "Intercultural interactions and cultural transformation", Asian journal of social psychology, Vol. 17 No. 2, pp. 100-103.

Lu, Y. and Hsu, C.-F. (2008), "Willingness to communicate in intercultural interactions between Chinese and Americans", Journal of Intercultural Communication Research, Vol. 37 No. 2, pp. 75-88.

Lustig, M.W. and Koester, J. (2006), Intercultural Competence: Interpersonal Communication Across Cultures, 5 ed., Pearson, Boston, MA.

Malik, A., Ngo, L. and Kingshott, R. (2018), "Power, resource-dependencies and capabilities in intercultural B2B relationships", Journal of Services Marketing, Vol. 32 No. 4.

Mathies, C. and Wong, A. (2018), "Service Models and Culture: Impact on Work Behaviours", Journal of Services Marketing, Vol. 32 No. 4.

Matsumoto, D. and Hwang, H.S. (2011), "Cooperation and competition in intercultural interactions", International Journal of Intercultural Relations, Vol. 35 No. 5, pp. 677-685. 
Mishra, A., Maheswarappa, S. and Colby, C. (2018), "Technology readiness of teenagers: A consumer socialization perspective", Journal of Services Marketing, Vol. 32 No. 4.

Morales, M. and Ladhari, R. (2011), "Comparative cross-cultural service quality: an assessment of research methodology", Journal of Service Management, Vol. 22 No. 2, pp. 241-265.

Paswan, A.K. and Ganesh, G. (2005), "Cross-Cultural Interaction Comfort and Service Evaluation", Journal of International Consumer Marketing, Vol. 18 No. 1/2, pp. 93-115.

Pezzuti, T., Pierce, M. and Leonhardt, J. (2018), "Does Language Homophily Affect Migrant Consumers' Service Usage Intentions?", Journal of Services Marketing, Vol. 32 No. 4.

Poulis, K., Poulis, E. and Yamin, M. (2013), "Multicultural markets and acculturation: implications for service firms", Journal of Services Marketing, Vol. 27 No. 7, pp. 515525.

Samovar, L.A., Porter, R.E. and Jain, N.C. (1981), Understanding intercultural communication, ed., Wadsworth Publishing Company, Belmont, CA.

Sanchez-Burks, J., Bartel, C.A. and Blount, S. (2009), "Performance in intercultural interactions at work: Cross-cultural differences in response to behavioral mirroring", Journal of Applied Psychology, Vol. 94 No. 1, pp. 216-223.

Schoefer, K. (2010), "Cultural Moderation in the Formation of Recovery Satisfaction Judgments: A Cognitive-Affective Perspective", Journal of Service Research, Vol. 12 No. 1, pp. 5266. 
Sharma, P., Kim, N., Yip, L. and Zhan, W. (2014). "Special Session: Intercultural Service Encounters \& Communication Issues". ANZMAC Annual Conference. Brisbane, Australia, pp.

Sharma, P., Sivakumaran, B. and Marshall, R. (2005), "Deliberate Self-Indulgence Vs. Involuntary Loss of Self-Control: Exploring the Influence of Culture on Consumer Impulsiveness Trait". European Advances in Consumer Research, Gothenburg, Sweden. pp. 593-594.

Sharma, P., Tam, J.L.M. and Kim, N. (2009), "Demystifying Intercultural Service Encounters: Toward a Comprehensive Conceptual Framework", Journal of Service Research, Vol. 12 No. 2, pp. 227-242.

Sharma, P., Tam, J.L.M. and Kim, N. (2012), "Intercultural Service Encounters (ICSE) Framework: Extension and Empirical Validation", Journal of Services Marketing, Vol. 26 No. 7, pp. 521-534.

Sharma, P., Tam, J.L.M. and Kim, N. (2015), "Service Role and Outcome as Moderators in Intercultural Service Encounters", Journal of Service Management, Vol. 26 No. 1, pp. 137-155.

Sharma, P., Tam, J.L.M., Kim, N., Zhan, W. and Su, Y. (2017), Intercultural service encounters (ICSEs): Challenges and opportunities for international services marketers. In: Leonidou, L.C., Katsikeas, C.S., Samiee, S. and Aykol, B. (eds.) Advances in Global Marketing: A Research Anthology. eBook: Springer, pp. 449-470. 
Sharma, P. and Zhan, W. (2015), "Consumer Ethnocentrism vs. Intercultural Competence as Moderators in Intercultural Service Encounters", Journal of Services Marketing, Vol. 29 No. 2, pp. 93-102.

Sharma, P., Zhan, W. and Su, Y. (2016), "Role of Personal Cultural Orientations in Intercultural Service Encounters", Journal of Services Marketing, Vol. 30 No. 2, pp. 223-237.

Sichtmann, C. and Micevski, M. (2018), "Attributions of Service Quality: Immigrant Customers’ Perspective", Journal of Services Marketing, Vol. 32 No. 4.

Stauss, B. and Mang, P. (1999), "'Culture Shocks" in Inter-cultural Service Encounters?", Journal of Services Marketing, Vol. 13 No. 4/5, pp. 329-346.

Stening, B.W. (1979), "Problems in cross-cultural contact: A literature review", International Journal of Intercultural Relations, Vol. 3 No. 3, pp. 269-313.

Summers, J., Hassan, R., Hossain, M. and Ong, D. (2018), "Australian Muslim Women and Fitness Choices - Myths Debunked", Journal of Services Marketing, Vol. 32 No. 4.

Tam, J.L.M., Sharma, P. and Kim, N. (2014), "Examining the Role of Attribution and Intercultural Competence in Intercultural Service Encounters", Journal of Services Marketing, Vol. 28 No. 2, pp. 159-170.

Tam, J.L.M., Sharma, P. and Kim, N. (2016), "Attribution of Success and Failure in Intercultural Service Encounters: Moderating Role of Personal Cultural Orientations", Journal of Services Marketing, Vol. 30 No. 6, pp. 643-658. 
Thomas, K.M. (1996), "Psychological privilege and ethnocentrism as barriers to cross-cultural adjustment and effective intercultural interactions", The Leadership Quarterly, Vol. 7 No. 2, pp. 215-228.

Tombs, A. and Rao Hill, S. (2014), "The effect of service employees’ accent on customer reactions", European Journal of Marketing, Vol. 48 No. 11/12, pp. 2051-2070.

Ueltschy, L.C., Laroche, M., Eggert, A. and Bindl, U. (2007), "Service quality and satisfaction: an international comparison of professional services perceptions", Journal of Services Marketing, Vol. 21 No. 6, pp. 410-423.

United Nations (2017). "International Migration Report 2017". New York: Department of Economic and Social Affairs, Population Division, pp. 1-46.

UNWTO (2018), Inbound Tourist Arrivals. World Tourism Barometer. Madrid, Spain: World Tourism Organization, pp. 1-23.

van Oudenhoven, J.P. and Benet-Martínez, V. (2015), "In search of a cultural home: From acculturation to frame-switching and intercultural competencies", International Journal of Intercultural Relations, Vol. 46 No. 1, pp. 47-54.

Wang, C.-y. and Mattila, A.S. (2010), "A grounded theory model of service providers' stress, emotion, and coping during intercultural service encounters", Managing Service Quality, Vol. 20 No. 4, pp. 328-342. 
Ward, C. (2008), "Thinking outside the Berry boxes: New perspectives on identity, acculturation and intercultural relations", International Journal of Intercultural Relations, Vol. 32 No., pp. 105-114.

Ward, C. and Kennedy, A. (2001), "Coping with Cross-Cultural Transition", Journal of CrossCultural Psychology, Vol. 32 No. 5, pp. 636 - 642.

Ward, C. and Rana-Deuba, A. (2000), "Home and host culture influences on sojourner adjustment", International Journal of Intercultural Relations, Vol. 24 No. 3, pp. 291-306.

Yu, J. and Lee, T.J. (2014), "Impact of tourists' intercultural interactions", Journal of Travel Research, Vol. 53 No. 2, pp. 225-238.

Zolfagharian, M., Hasan, F. and Iyer, P. (2018), "Customer Response to Service Encounter Linguistics", Journal of Services Marketing, Vol. 32 No. 4. 


\section{Customer perceptions in intercultural} service encounters e.g., culture shock (Stauss and Mang, 1999), perceived discrimination (Barker and Härtel, 2004), cross-cultural interaction comfort (Paswan and Ganesh, 2005), consumer

ethnocentrism (Javalgi and Martin, 2007; Sharma et al., 2005; Ueltschy et al., 2007), perceived cultural distance, interaction comfort, inter-role congruence, intercultural competence (Sharma et al., 2009, 2012).

\section{Customer responses in intercultural} service encounters e.g., customer reactions to ethnic/cultural dissimilarity with servicce employees (Etgar and Fuchs, 2011), service failure and recovery (de Matos et al., 2011), employee's acculturation behaviours (Poulis et al., 2013), ethnic accents (Tombs and Rao Hill, 2014); stereotyping of culturally different service employees by customers (Hopkins et al., 2005; Javalgi and Martin, 2007; Ueltschy et al., 2007), perceived discrimination by service employees

\section{Antecedents of customer and employee perceptions and behaviours in intercultural service encounters e.g., attentiveness (Lee,} 2015), acculturation behaviours (Gaur et al., 2017) and linguistic choices of frontline service employees (Zolfagharian et al., 2018), language homophily between customers and employees (Pezzuti et al., 2018), perceived cultural distance and customer participation (Ang et al., 2018), customer-employee (mis)match and cultural vs. non-cultural attributions (Sichtmann and Micevski, 2018), Intercultural competence and customer facial recognition (Henderson et al., 2018), Technology readiness and consumer socialization of teenagers (Mishra,

Maheswarappa and Colby, 2018), religiosity and consumer choice of fitness services (Summers et al., 2018), Impact of service models and culture on work behaviours (Mathies and Wong, 2018).

\section{Moderators of customer and employee} perceptions and behaviours in intercultural service encounters e.g., service role and outcome (Sharma et al., 2015), consumer ethnocentrism and intercultural competence (Sharma and Zhan, 2015), intercultural communication competence
- Service employees' perspective in multicultural marketplaces in terms of the diversity in their expectations, perceptions and evaluations as well as differences with culturally close versus distant customers.

- Insights into the multicultural Business-to-business (B2B) contexts involving both mono and multicultural organisational units.

- Unique challenges posed by multicultural service workplaces in terms of inter-cultural friction, crosscultural adjustment etc.

- Differences in the impact of individual-level personal cultural orientations and national-level cultural dimensions on customers and employees involved in intercultural service encounters.

- Interactive impact of cultural, socioeconomic and demographic variables 
(Barker and Härtel, 2004) and crosscultural consumer to consumer

interactions (Johnson and Grier, 2013).

Employee perceptions and responses in intercultural service encounters e.g., employee stress and coping (Wang and Mattila, 2010), emotional labour

(Chuapetcharasopon, 2014), preference for ethnic service staff (Baumann and Setogawa, 2014).
(Ihtiyar and Ahmad, 2015), and personal cultural orientations (Sharma et al., 2016).

\section{Mediators of customer and employee} perceptions and behaviours in intercultural service encounters e.g., attributions (Tam et al., 2014; Tam et al., 2016) and intercultural service quality (Fung et al., 2017).

Antecedents and outcomes of intercultural B2B relationships e.g., power, resourcedependencies and capabilities (Malik, Ngo and Kingshott, 2018). on the expectations, perceptions and evaluations of increasingly culturally diverse customers and employees in multicultural marketplaces

- Differentiate and investigate the role of constructs such as intercultural competence, intercultural sensitivity and cultural intelligence in intercultural service encounters

- Explore the differences in the crosssectional versus developmental view of cross-cultural adjustment and adaptation process for culturally diverse customers and employees 